UDC 347.952 .3

Submitted: 17.09.2018

LBC 67.410 .1

Accepted: 22.10 .2018

\title{
INDIRECT MEASURES OF COMPULSION OF THE DEBTOR TO PAY ARREARS OF MAINTENANCE OBLIGATIONS ${ }^{1}$
}

\author{
Evgeniy N. Kuznetsov \\ Ural State Law University, Ekaterinburg, Russian Federation
}

\begin{abstract}
Introduction: the article deals with some problems of the Russian enforcement proceedings in cases related to the payment of alimony. The high social significance of the system of meeting alimony obligations is determined. The statistical reporting of activities of the Russian law enforcement bodies showing the existence of significant problems in the analyzed sphere is given. The purpose of the work is to propose the creation of a system of measures of indirect compulsion of the debtor to perform his duties. The tasks are the problem statement, the identification of the public importance of the problematics, the analysis of the statistical data, and the offer of the problem solving techniques by means of the active use of measures of indirect compulsion of the debtor to meet his/her maintenance obligations. The statistical and system-logical methods of research are used. Results: the specific measures of indirect compulsion of the debtor in order to improve the efficiency of the Russian enforcement proceedings in alimony cases are proposed, the idea of the importance of creating a situation, in which to have the status of the debtor, especially on maintenance obligations, will be extremely disadvantageous for any citizen, is formulated. Conclusions: it is proposed to create a system of restrictions on the rights of the debtor, in the implementation of which the state is involved, including a systematic restriction of a number of rights of debtors on maintenance obligations, the right to register real estate, the right to marry or dissolve marriage, to hold certain positions, restrictions on the disposal of funds available in the accounts of the debtor, restrictions on the use of the system of railway and air transport, the termination of the right to receive tax deductions and benefits, any social benefits, the prohibition on renewal of the passport of the citizen of the Russian Federation, the foreign passport, the driver's license, the birth certificate of the child and so on.
\end{abstract}

Key words: enforcement proceedings, socially important activities, family legal relationship, child support, alimony, executor.

Citation. Kuznetsov E.N. Indirect Measures of Compulsion of the Debtor to Pay Arrears of Maintenance Obligations. Legal Concept, 2018, vol. 17, no. 4, pp. 141-147. DOI: https://doi.org/10.15688/lc.jvolsu.2018.4.20

\section{КОСВЕННЫЕ МЕРЫ ПРИНУЖДЕНИЯ ДОЛЖНИКА К ВЫПЛАТЕ ЗАДОЛЖЕННОСТИ ПО АЛИМЕНТНЫМ ОБЯЗАТЕЛЬСТВАМ ${ }^{1}$}

\section{Евгений Николаевич Кузнецов}

Уральский государственный юридический университет, г. Екатеринбург, Российская Федерация

Введение: в статье рассматриваются отдельные проблемы российского исполнительного производства по делам, связанным с уплатой алиментов. Определяется высокая социальная значимость системы исполнения по алиментным обязательствам. Приводится статистическая отчетность деятельности органов принудительного исполнения России, указывающая на существование значимых проблем в анализируемой сфере. Цель работы - предложить создание системы мер косвенного принуждения должника к исполнению обязанностей. Задачи: постановка проблемы, выявление общественной значимости проблематики, анализ статистических данных, предложение способов решения проблематики за счет активного использования мер косвенного принуждения должника к исполнению своих алиментных обязательств. Использованы стати- 
стический и системно-логический методы исследования. Результаты: предложены конкретные меры косвенного принуждения должника в целях повышения эффективности российского исполнительного производства по алиментным делам, сформулирована идея о важности создания такой ситуации, при которой иметь статус должника, особенно по алиментным обязательствам, будет крайне невыгодно для любого гражданина. Выводы: предложено создание системы ограничений прав должника, в реализации которых участвует государство, в том числе системное ограничение ряда прав должников по алиментным обязательствам, права регистрации недвижимого имущества, права на вступление в брак или расторжение брачного союза, занимать определенные должности, ограничения в распоряжении денежными средствами, имеющимися на счетах должника, ограничения в использовании системы железнодорожного и авиатранспорта, прекращение права на получение налоговых вычетов и льгот, любых льгот социального характера, запрет на переоформление паспорта гражданина Российской Федерации, заграничного паспорта, водительского удостоверения, свидетельства о рождении ребенка и пр.

Ключевые слова: исполнительное производство, социально значимые дела, семейные правоотношения, алименты, взыскание алиментов, судебный исполнитель.

Цитирование. Кузнецов Е. Н. Косвенные меры принуждения должника к выплате задолженности по алиментным обязательствам // Legal Concept = Правовая парадигма. -2018 . - T. 17, № 4. - C. 141-147. DOI: https://doi.org/10.15688/lc.jvolsu.2018.4.20

\section{Введение}

Современное состояние российского исполнительного производства переживает далеко не самые лучшие времена. Предпринимаемые меры по совершенствованию норм гражданского исполнительного права характеризуются бессистемностью, направлены на решение частных вопросов и далеки от комплексного подхода к совершенствованию процедур принудительного исполнения $[4$, с. $17-$ 26]. Меры принудительного исполнения, предпринимаемые судебным приставом-исполнителем, не всегда позволяют достичь подлинной цели системы исполнительного производства - своевременного и правильного исполнения требований исполнительного документа. Целью настоящей статьи является выявление возможностей повышения эффективности российской системы исполнительного производства через более активное внедрение косвенных мер принуждения должника к исполнению своих обязанностей в одной из самых острых социальных сфер - семейных правоотношениях, и особенно в сфере взыскания алиментов.

\section{Постановка проблемы}

Сущность семейных правоотношений предполагает наличие во взаимосвязи между их субъектами не столь формальных и деловых правовых аспектов, как, например, в гражданских правоотношениях. На их содержание влияет множество самых разных факторов, среди которых правовые вопросы занимают далеко не первое место. Семейные споры, возникающие из соответствующих отношений, характеризуются эмоциональным отношением сторон к сложившейся ситуации, частым использованием правовых способов защиты своих интересов в формате злоупотребления правом, различными способами затягивания процедуры судебного рассмотрения дела. Как правило, даже после вынесения судебного акта сам по себе конфликт так и не исчерпан. Это дает сторонам возможность повторно запустить механизм судебной защиты - в формате апелляционных и кассационных жалоб, что в целом усложняет процесс защиты права заинтересованного в получении алиментов лица. Итогом такой деятельности является, как правило, обращение последнего в органы принудительного исполнения за принудительной реализацией требований, указанных в исполнительном документе, то есть путем применения к должнику таких мер государственного принуждения, которые он обязан претерпеть.

Приходится констатировать, что российское исполнительное производство в таких условиях является, по сути, последней гранью правового конфликта между сторонами семейного спора, где судебный пристависполнитель ставит точку в защите права конкретного лица. Это, в свою очередь, воз- 
лагает на него высокий уровень социальной ответственности.

Если же речь идет о взыскании алиментной задолженности в пользу несовершеннолетних детей или нетрудоспособных родителей, ситуация приобретает еще более острый социальный характер, поскольку характеризуется, как правило, непониманием одной стороной спора причин, по которым лицо, обязанное по закону обеспечивать своих несовершеннолетних детей или нетрудоспособных родителей, избегает исполнения своих обязанностей. Закон же здесь неумолим - ст. 38 Конституции РФ указывает, что одной из важнейших государственных задач является защита материнства и детства. Эта идея находит отражение в нормах семейного права, согласно которым родители обязаны заботиться о детях, их воспитании, а трудоспособные граждане, достигшие 18 лет, должны заботиться о своих нетрудоспособных родителях (гл. 13 Семейного кодекса РФ).

Взглянув на статистические данные, представленные для всеобего сведения на официальном сайте Федеральной службы судебных приставов [1], можно увидеть, что взыскание алиментов является одной из самых серьезных задач (и проблем) в деятельности службы, поскольку такие правоотношения имеют длящийся характер, количество дел в производствах судебных приставов-исполнителей не уменьшается, а сумма взыскиваемой задолженности в целом по
ФССП за годовой период заставляет задуматься о поиске иных, чем установленные ныне Федеральным законом «Об исполнительном производстве», мер принудительного исполнения и косвенного принуждения должника к исполнению своих обязанностей (см. таблицу).

Во-первых, достаточно странной представляется ситуация, что из года в год статистика дел по ряду позиций остается примерно одинаковой - количество исполнительных производств, количество фактически оконченных или прекращенных производств и т. д. Во-вторых, цифры явно свидетельствуют о том, что действующая модель принудительного исполнения попросту не справляется с объемом дел, находящихся в производстве судебных приставов-исполнителей: так, из 1,5 млн исполнительных производств в 2017 г. на сумму 179 млн руб. окончено лишь 730 тыс. дел, фактическим исполнением - всего 55 тыс., на общую сумму 9,8 млн рублей. Добровольно исполнено всего 47 тыс. исполнительных производств... То есть при взыскании задолженности с должников по алиментным обязательствам на сумму более чем 170 млн руб. не была создана ситуация, при которой должник самостоятельно и добровольно погасил накопившуюся задолженность. И таким образом на следующий год перешла задолженность на общую сумму более 130 млн рублей. Ситуация повторяется ежегодно.

\section{Динамика развития исполнительного производства России по делам о взыскании алиментов}

\begin{tabular}{|c|c|c|c|}
\hline Позиции статистики & 1 полугодие 2018 года & 2017 год & 2016 год \\
\hline $\begin{array}{l}\text { Количество исполни- } \\
\text { тельных производств }\end{array}$ & 1196004 & 1579258 & 1608133 \\
\hline $\begin{array}{l}\text { Размер взыскиваемой } \\
\text { задолженности }\end{array}$ & 158777669 руб. & 179978821 & 176315139 руб. \\
\hline $\begin{array}{l}\text { Окончено или прекра- } \\
\text { щено, на сумму }\end{array}$ & $\begin{array}{c}358921, \\
22980053 \text { руб. }\end{array}$ & $\begin{array}{c}731923, \\
40509684 \text { руб. }\end{array}$ & $\begin{array}{c}730880, \\
34434912 \text { руб. }\end{array}$ \\
\hline $\begin{array}{l}\text { Фактическим исполне- } \\
\text { нием завершено, на } \\
\text { сумму }\end{array}$ & $\begin{array}{c}24682, \\
2694846 \text { руб. }\end{array}$ & $\begin{array}{c}55351, \\
9892812 \text { руб. }\end{array}$ & $\begin{array}{c}58462, \\
12503248 \text { руб. }\end{array}$ \\
\hline $\begin{array}{l}\text { Добровольно исполнено } \\
\text { должниками }\end{array}$ & $\begin{array}{c}19620 \text { исполнительных } \\
\text { производств }\end{array}$ & $\begin{array}{c}47884 \text { исполнительных } \\
\text { производств }\end{array}$ & $\begin{array}{c}48468 \text { исполнительных } \\
\text { производств }\end{array}$ \\
\hline $\begin{array}{l}\text { Остаток исполнитель- } \\
\text { ных производств на ко- } \\
\text { нец отчетного периода, } \\
\text { на сумму }\end{array}$ & $\begin{array}{c}836306, \\
132031630 \text { руб. }\end{array}$ & $\begin{array}{c}844850, \\
130689520 \text { руб. }\end{array}$ & $\begin{array}{c}874810, \\
132507328 \text { руб. }\end{array}$ \\
\hline
\end{tabular}




\section{Способы усиления эффективности исполнительного производства}

Очевидно, что действующая система мер принудительного исполнения, предусмотренная действующим законодательством, к должнику по алиментным обязательствам применяется неэффективно. Можно даже сказать - крайне неэффективно. В силу длящегося характера данных правоотношений важно не только искать и арестовывать имущество должника - эта мера носит временный характер и, скорее всего, потребует совершения подобных действий в отношении должника повторно, в случае накопления им новой задолженности. При этом не очевидно, что у последнего к моменту повторного применения мер принудительного исполнения появится новое имущество.

Одной из самых эффективных мер принудительного исполнения по делам о взыскании алиментов является наложение ареста на заработную плату, но не секрет, что применение и данной меры далеко от совершенства должник может быть не трудоустроен официально, а по договору, в котором указан лишь минимальный размер оплаты труда, может договориться с работодателем об официальном указании меньшего размера своих доходов и т. д. Кроме того, показывают эффективность совместные рейды судебных приставов-исполнителей и органов ГИБДД, в ходе которых сотрудники полиции останавливают участников дорожного движения, судебный пристав-исполнитель проверяет наличие у них задолженности и в случае обнаружения таковой тут же налагает арест на транспортное средство. Сложность здесь возникает в соизмеримости размера алиментной задолженности со стоимостью транспортного средства, а также с тем, что фактически принадлежащий должнику автомобиль может формально-юридически находиться на праве собственности у другого лица.

Важно создавать систему таких мер воздействия на должника, при которых он будет сам предпринимать действия, направленные на предупреждение возникновения у него задолженности [3, с. 49-55]. Очевидно, что цель таких мер - фактическое побуждение должника к чрезвычайно активным и самостоя- тельным действиям, направленным на погашение имеющейся задолженности, на своевременную оплату текущих алиментных платежей и на недопущение возникновения задолженности впредь, - заставляет нас искать такие пути, которые помимо предусмотренных правовыми нормами инструментов защиты потребуют решения ряда вопросов экономического, политического и социального характера.

Это потребует времени, но способно будет реально создать ситуацию, при которой, во-первых, будут реально достигнуты целевые установки законодательства о судопроизводстве (защита нарушенных или оспариваемых прав, свобод, законных интересов); во-вторых, существенно усилится эффективность исполнительного производства (в силу снижения нагрузки на судебных приставов-исполнителей); в-третьих, в обществе начнется формирование понимания важности и необходимости исполнения требований, заложенных в исполнительных документах (что усилит обратную связь «общество - должник», когда на последнего будет «давить общественное мнение»); в-четвертых, повысится социальная ответственность должника, его внутреннее отношение к сложившейся ситуации, что способно будет привести к созданию ситуации, когда алименты по общему правилу будут выплачиваться без прохождения заинтересованным лицом механизма судебной защиты.

Для решения данной задачи необходимо сконцентрировать усилия ученых-правоведов, законодателя и правоприменителя на формировании целой системы косвенных мер принуждения должника к взысканию задолженности по алиментным обязательствам. При этом важно понимать, что именно такие меры, которые, безусловно, будут направлены на ограничение должника в определенных правах, возможно, самых значимых для него, как раз и будут показывать максимальную эффективность. Речь идет о «мягком принуждении», когда выбор варианта поведения остается за должником, но по сути создается ситуация «выбор без выбора», поскольку ограничение должника в конкретном праве существенно повлияет (и именно должно повлиять!) на его жизнедеятельность, сферу занятости и уровень заработка $[2$, с. 17]. Такие меры следует проработать, про- 
верить в экспериментальном режиме и зафиксировать в случае подтверждения их эффективности в нормах законодательства об исполнительном производстве. При этом применение таких мер не следует рассматривать как умаление прав. Это обусловлено, во-первых, возможностью ограничения прав в случаях, предусмотренных в законе (ст. 55 Конституции РФ); во-вторых, необходимо учитывать, что такие меры применяются лишь к должникам по алиментным обязательствам, в самой острой сфере взаимоотношений между людьми, где напрямую речь идет об интересах несовершеннолетних детей и нетрудоспособных родителей. Задолженность может возникнуть либо на основании исполнительного документа, либо из фактической ситуации: то, что заинтересованное в получении алиментов лицо или его законный представитель не обратились в суд, еще не означает отсутствие обязательства должника по уплате алиментов, предусмотренного нормами материального права. Возникновение задолженности по алиментам означает, что конкретный гражданин в силу любых причин игнорирует прямое предписание действующего законодательства. При таком угле зрения на ситуацию применение мер косвенного воздействия будет оправданно и крайне эффективно.

Основными направлениями работы по созданию целостной системы мер косвенного принуждения должников по алиментным обязательствам могут стать следующие (при этом все меры являются временными, действуя до полного погашения должником суммы накопленной задолженности):

1. Сохранение и дальнейшее развитие действующих косвенных мер принуждения: ограничение на выезд за пределы Российской Федерации, временные ограничения в пользовании специальным правом (ст. 67, 67.1 Федерального закона «Об исполнительном производстве»).

2. Более активное применение возможности запрета на проведение регистрационных действий с авто- и мототранспортными средствами, любыми иными средствами транспорта, включая воздушные и водные, подлежащими регистрации.

3. Ограничение права на регистрацию сделок с недвижимым имуществом.
4. Ограничение права на регистрацию браков и их расторжение.

5. Прекращение права на получение налоговых вычетов и льгот, любых льгот социального характера.

6. Ограничение права пользования системой общественного транспорта (железнодорожное и авиасообщение российскими авиалиниями).

7. Введение ограничения на использование собственных денежных средств на банковских счетах минимальной суммой (например, до 3 тыс. рублей в неделю).

8. Запрет на переоформление ряда документов в связи с истечением срока их действия - водительского удостоверения, заграничного паспорта, паспорта гражданина Российской Федерации, а также выдачи любых документов, исходящих от органов государственной власти или органов местного самоуправления (например, свидетельства о рождении ребенка, ИНН).

9. В случае злостности неуплаты алиментов возможно применение указанных выше мер к членам семьи должника как косвенный способ воздействия на него.

10. Запрет занимать государственные должности высокого уровня (высшие, главные и ведущие должности гражданской службы - ст. 9 Федерального закона «О государственной гражданской службе Российской Федерации»), выборные должности любого уровня, в том числе на уровне муниципалитета и даже конкретных юридических лиц (например, председатель товарищества собственников жилья, дачного некоммерческого партнерства и т. п.). В случае присуждения такого лица к уплате алиментов данный запрет может быть установлен лишь при условии образования у него задолженности как у злостного неплательщика.

11. Повышение социальной ответственности должника через размещение социальной рекламы о необходимости погашения им задолженности с указанием ФИО и фотографии должника, размера суммы долга и времени просрочки (местное телевидение, социальные сети, контекстная реклама в интернете). С учетом целевых установок принимаемой меры ряд положений закона о защите персональных данных не должен применяться, как и ссылки должника на недопустимость 
распространения информации о нем. В отношении индивидуальных предпринимателей уже высказывались справедливые предложения о включении их в реестр недобросовестных поставщиков [3].

12. Развитие в целом системы социальной рекламы на телевидении, радио, в социальных сетях с активной пропагандой необходимости исключения ситуаций, связанных с возникновением у гражданина задолженности по алиментам.

13. Введение в законе возможности распространения судебным приставом-исполнителем информации об алиментной задолженности по месту работы, месту жительства должника.

14. Более активное применение института медиации, внедрение ее как обязательного предварительного этапа перед обращением заинтересованного лица в суд с требованием о взыскании алиментов, что способно снизить уровень конфликтности ситуации, поскольку медиатор обеспечивает такую процедуру переговоров, когда договоренностей достигают сами стороны с учетом интересов друг друга.

Безусловно, применение каждой меры требует предварительного анализа возможных сложностей при реализации, однако создание ситуации, при которой должнику будет крайне невыгодно иметь подобный статус, как раз позволит повысить эффективность взыскания алиментных платежей и существенно разгрузить судебных приставов-исполнителей для реализации иных исполнительных производств, на решении вопросов по сложным исполнительным производствам. Применение каждой из мер должно отвечать требованиям соразмерности с содержанием обязательства, с конкретной суммой задолженности и той жизненной ситуацией, в которой должник сам фактически находится.

\section{Заключение}

В целях повышения эффективности исполнительного производства по взысканию алиментов очень важно создать комплексную систему мер косвенного принуждения должника. Кроме того, необходимо вести просветительскую работу по внедрению идеи понимания исключительной значимости соблюдения законо- дательных предписаний и ее реализации в действиях конкретных субъектов семейных правоотношений. Необходимо создать ситуацию, когда быть должником - крайне невыгодно, осуждение близких и общества способно еще больше усилить эффективность таких мер.

В условиях продолжения работы над проектом Исполнительного кодекса целесообразно в отдельной главе разработать законодательную регламентацию мер косвенного принуждения должника через ограничение реализации им отдельных прав, в ходе обеспечения которых задействовано государство. В качестве пилотного проекта возможно запустить применение этой системы в отдельных субъектах Российской Федерации, взяв за основу именно алиментные обязательства. Полученные за определенный период результаты необходимо оценить, адаптировать их к еще более эффективному применению. Важно, чтобы у истоков такой работы стоял основной орган государственной власти, ответственный за соответствующую сферу деятельности, - Министерство юстиции Российской Федерации при активнейшем участии Федеральной службы судебных приставов. Эффективность их работы можно будет определить по изменениям в статистических данных, касаемых взыскания алиментных платежей, повышения уровня добровольности исполнения соответствующих требований со стороны должников.

\section{ПРИМЕЧАНИЕ}

\begin{abstract}
${ }^{1}$ Статья выполнена в рамках выполнения государственного задания по проекту № 29.8235.2017/ 8.9 по теме: «Анализ состояния и разработка концепции совершенствования исполнительного производства Российской Федерации по социальнозначимым делам».
\end{abstract}

\section{СПИСОК ЛИТЕРАТУРЫ}

1. Ведомственная статистическая отчетность Федеральной службы судебных приставов за 1 полугодие 2018 года, за 2017 год, за 2016 год. - Электpoн. текстовые дан. - Режим доступа: http:// fssprus.ru/statistics/ (дата обращения: 11.10.2018). Загл. с экрана. 
E.Н. Кузнецов. Косвенные меры принуждения должника к выплате задолженности по алиментным обязательствам

2. Гальперин, М. Л. Исполнительные действия - меры ответственности? / М. Л. Гальперин // Lex Russica. - 2018. - № 3. - C. 9-21.

3. Парфенчикова, А. А. Косвенные меры принудительного исполнения в исполнительном производстве / А. А. Парфенчикова, К. А. Малюшин // Арбитражный и гражданский процесс. - 2016. № 2. - С. 49-55.

4. Парфенчиков, А. О. Ограничение прав должника: новеллы законодательства и практика применения / А. О. Парфенчиков // Сборник материалов Международной научно-практической конференции / отв. ред. А. О. Парфенчиков, В. А. Гуреев. - М., 2016.

\section{REFERENCES}

1. Vedomstvennaya statisticheskaya otchetnost Federalnoy sluzhby sudebnykh pristavov za 1 polugodie 2018 goda, za 2017 god, za 2016 god
[Departmental Statistical Reporting of the Federal Bailiff Service for the $1^{\text {st }}$ Half of 2018, for 2017 and for 2016 Years]. URL: http://fssprus.ru/statistics/. (accessed 11 October 2018).

2. Galperin M.L. Ispolnitelnye deystviya - mery otvetstvennosti? [Executive Actions - Measures of Responsibility?]. Lex Russica, 2018, no. 3, pp. 9-21.

3. Parfenchikova A.A., Malyushin K.A. Kosvennye mery prinuditelnogo ispolneniya $\mathrm{V}$ ispolnitelnom proizvodstve [Indirect Measures of Compulsory Execution in Enforcement Proceedings]. Arbitrazhnyy i grazhdanskiy protsess, 2016, no. 2, pp. 49-55.

4. Parfenchikov A.O. Ogranichenie prav dolzhnika: novelly zakonodatelstva i praktika primeneniya [Limiting the Rights of a Debtor: Novelties of Legislation and Practice of Using]. Parfenchikov A.O., Gureev V.A., eds. Sbornik materialov Mezhdunarodnoy nauchno-prakticheskoy konferentsii [Collected Materials of the International Research and Practice Conference]. Moscow, 2016.

\section{Information about the Author}

Evgeniy N. Kuznetsov, Candidate of Sciences (Jurisprudence), Associate Professor of Department of Civil Procedure, Ural State Law University, Komsomolskaya St., 21, 620137 Ekaterinburg, Russian Federation, Corben2002@mail.ru, https://orcid.org/0000-0001-7787-0328

\section{Информация об авторе}

Евгений Николаевич Кузнецов, кандидат юридических наук, доцент кафедры гражданского процесса, Уральский государственный юридический университет, ул. Комсомольская, 21, 620137 г. Екатеринбург, Российская Федерация, Corben2002@mail.ru, https://orcid.org/0000-0001$7787-0328$ 